\title{
Alcohol Consumption in India: An Analysis of IHDS Data
}

\author{
Nasim Ahamed Mondal' ${ }^{*}$, Mithun Mog $^{2}$, Kacho Amir Khan ${ }^{3}$ \\ ${ }^{* 1}$ Project Officer, International Institute for Population Sciences, Mumbai, Maharashtra, India. \\ ${ }^{2}$ Senior Research Officer, International Institute for Population Sciences, Mumbai, Maharashtra, India. \\ ${ }^{3}$ Doctoral Fellow, International Institute for Population Sciences, Mumbai, Maharashtra, India. \\ *nasimamu32@gmail.com
}

\begin{abstract}
Introduction: Harmful use of alcohol result in 3 million people die each year, which means $5.3 \%$ of all deaths worldwide. Alcohol has a contribution on the global burden of disease and injury which accounts approximately 5.1 per cent of the disability-adjusted life years (DALYs), and approximately 13.5 per cent of the total deaths in the age group 20-39 years were caused by alcohol consumption.

Objectives: To understand the changes and differentials in alcohol consumption in India and its states, and to examine the determinants of alcohol consumption in India.

Data Source and Methodology: The present study has used the national representative Indian Human Development Surveys (IHDS) I (2004-05) and II (2011-12). Bivariate analysis was used to show the prevalence of alcohol consumption concerning some selected socioeconomic and demographic background variables. The Chi-square and multivariate logistic regressions were also employed to estimate the odds ratio (95\% CI) for alcohol consumption. STATA and Arc GIS 10.1 software were employed to carry out the analyses.

Findings: The alcohol consumption was two per cent higher in 2004-05 (37\%) than the recent survey of IHDS (2011-12) (35\%) in India. In addition to that, there were some states where the consumption of alcohol had increased from 2004 to 2012 like Mizoram (44\%), Kerala (19\%), and Jammu and Kashmir (16\%). In contrary to that, there were also a few states where alcohol consumption had decreased from 2004 to 2012 like Rajasthan (8\%) and Tamil Nadu (5\%).
\end{abstract}

Keywords: Alcohol, prevalence, determinants of drinking, India

\section{INTRODUCTION}

If we look at the world scenario, around half (43\%, or 2.3 billion) of the world's population aged 15 years and over have consumed alcohol in the previous 12 months in 2016 (WHO, 2018). Although per capita consumption of alcohol is highest among adult in high-income countries, it is nearly as high in the upper-middle-income countries (Easwaran et al., 2015). As per the WHO report, per capita consumption of alcohol was 6.2 litres in 2010 aged 15 years or older worldwide (WHO, 2014). Harmful use of alcohol result in 3 million people die each year, which means $5.3 \%$ of all deaths worldwide (WHO, 2018). This report also revealed that alcohol has a contribution on the global burden of disease and injury which accounts approximately 5.1 per cent of the disability-adjusted life years (DALYs), and approximately 13.5 per cent of the total deaths in the age group 20-39 years were caused by alcohol consumption. About 60 per cent of all injuries to the emergency ward was due to alcohol use as shown by a hospital-based study (Benegal et al., 2002), and another study showed that 18 per cent of all brain injuries reporting to emergency ward were caused by alcohol usage (Gururaj et al., 2005). Looking at the Indian scenario, a countrywide survey showed that the prevalence of alcohol consumption was 21 per cent among men and 2 per cent of women in India (Ray, 2004). A study also found that alcohol consumption is not uniform but varies from 7\% in Gujarat to 75\% in Arunachal Pradesh (Bhullar et al., 2013). 
Another study showed that the prevalence of alcohol use in India is reported to be 21.4 per cent (Sarkar et al., 2013). A study by Prasad (2009) showed that India is still one of the lowest alcohol consumer countries in the world, government statistics showed only 21 per cent of adult men and around 2 per cent of women drink (Prasad, 2009).

There are a number of factors at the individual and social levels which determine the level of alcohol consumption such as: Age (Singh and Mail, 2014; Nadkarni et al., 2013; Goodwin et al., 1987; Wilsnack et al., 2009; Australian Institute of Health and Welfare, 2010), Sex (Singh and Mail, 2014; Goodwin et al., 1987; Wilsnack et al., 2009; Roche and Deehan, 2002; Rahav et al., 2006), Employment status (Nadkarni et al., 2013; Berry et al., 2007), Socioeconomic status (Nadkarni et al., 2013; Goodwin et al., 1987; Neufeld et al., 2005; Rehm et al., 2009; Schmidt et al., 2010; Huckle et al., 2010; Casswell et al., 2003), Family factor (Singh and Mail, 2014; Pandey et al., 2015; Thappa et al., 2016; Rice et al., 1998), Drinker's behavior (Singh and Mail, 2014), Alcohol exposure (volume, patterns, and quality of alcohol consumed) (Singh and Mail, 2014), Economic development (Singh and Mail, 2014), Culture (Singh and Mail, 2014), Existing alcohol-related policies (Singh and Mail, 2014), Education (Easwaran et al., 2015; Nadkarni et al., 2013; Goodwin et al., 1987; Neufeld et al., 2005; Thappa et al., 2016), Smoking and paternal history of alcohol consumption (Easwaran et al., 2015), Better health status (Nadkarni et al., 2013), Lower chronic morbidity (Nadkarni et al., 2013), Place of residence (Bhullar et al., 2013; Neufeld et al., 2005; Australian Institute of Health and Welfare, 2010), Climatic and geographical location (Pandey et al., 2015; Thappa et al., 2016; Rice et al., 1998), Availability of alcohol (Babor et al., 2010), Marital status (Liang and Chikritzhs, 2012; Boden et al., 2013; Matzger et al., 2004), Religion (Chowdhury et al., 2006; Subramanian et al., 2005; Gupta et al., 2003). Alcohol consumption has been a focal theme in public health problems in recent days. Hence, it has become necessary to know the prevalence and determinants of alcohol consumption to recommend control measures. The present study was carried out to measure the prevalence and determinants of alcohol consumption in India.

\section{ОВJECTIVES}

1. To understand the changes and differentials in alcohol consumption in India and its states.

2. To examine the determinants of alcohol consumption in India.

\section{METHODS}

\section{Data Source}

The present study has used the national representative Indian Human Development Surveys (IHDS) I (200405) and II (2011-12). The survey comprised all states and union territories of India except Lakshadweep and Andaman \& Nicobar Island. The Indian Human Development Survey-II, 2011-12 is a multi-topic survey of 42,152 households in 1,503 villages and 971 urban neighbourhoods across India. This survey collects information on health, education, employment, economic status, marriage, fertility, gender relations, and social capital.

The present study showed the changes of alcohol consumption from 2004 (India Human Development Survey first round) to 2011 (India Human Development Survey second round), but the categories of alcohol consumption were not same in the two rounds of India Human Development Survey. There were only three categories ("Never", "Sometimes", and "Daily") in the first round of India Human Development Survey whereas second round had four categories ("Never", "Rarely", "Sometimes", and "Daily"). So, we have categorised the alcohol consumption into two categories, i.e. "never" and "ever" for easy comparison as well as in understanding. In the first round of India Human Development Survey, "Never" labels the percentage of people who never had alcohol, and "Ever" comprises of percentage of people who had alcohol on sometimes and daily basis, whereas in the second round of India Human Development Survey "Never" labels the percentage of people who never had alcohol, and "Ever" comprises of percentage of people who had alcohol on rarely, sometimes and daily basis. 


\section{Study Settings}

We have selected all the states and union territories of India except Lakshadweep and Andaman \& Nicobar Island (These two state/UT excluded from the survey itself).

\section{Variable Measures}

Outcome Variable: The alcohol consumption was utilized as the outcome or dependent variable in the study.

Explanatory Variables: Age group, Sex, Place of residence, Religion, Caste, Economic status, Education, Migration status have been selected as independent variables.

\section{Statistical Analysis}

Bivariate analysis was used to show the prevalence of alcohol consumption concerning some selected socioeconomic and demographic background variables. The Chi-square and multivariate logistic regressions were also employed to estimate the odds ratio (95\% CI) for alcohol consumption. STATA and Arc GIS 10.1 software were employed to carry out the analyses.

\section{RESULTS}

Table 1 depicts the percentage distribution of alcohol consumption in India and its States (IHDS, 2004-05). The study has found 62.6 per cent of India's population never consume and remaining 37.4 per cent have used frequently (Sometimes \& Daily together). The study has also found that there are three states/UTs (Bihar, Daman \& Diu, and Dadra \& Nagar Haveli) which had more than 30 per cent consumption of alcohol on a daily basis. Moreover, alcohol consumption of sometimes basis has found 50 or more than 50 per cent in the eight states/UTs (Punjab, Chandigarh, Sikkim, Arunachal Pradesh, Nagaland, Chhattisgarh, and Pondicherry).

Table 2 expounds the percentage distribution of alcohol consumption in India and its States (IHDS 2011-12). There were seven states/UTs (Pondicherry, Goa, Andhra Pradesh, Daman \& Diu, Dadra Nagar Haveli, Arunachal Pradesh, and Sikkim) which had 20 per cent or more use of alcohol on a daily basis. 21 states/UTs had 20 or more than 20 per cent sometimes alcohol users whereas, only four states were found which had 20 per cent or more in the rare basis of alcohol consumption.

Tables 3 and 4 compare the ever use and never use of alcohol from 20004-05 to 2011-12 by states. In IHDS 2004-05, Around 63 per cent were never consumed alcohol, and the remaining 37 per cent were ever consumed of alcohol. However, table 1.4 shows that 65 per cent never used alcohol and 35 per cent were ever consumed of alcohol. Therefore, the alcohol consumption was two per cent higher in 2004-05 than the recent survey of IHDS (2011-12) in India. In addition to that, there were some states where the consumption of alcohol had increased from 2004 to 2012 like Jammu and Kashmir (16\%), Mizoram (44\%) and Kerala (19\%). In contrary to that, there were also a few states where alcohol consumption had decreased from 2004 to 2012 like Rajasthan (8\%) and Tamil Nadu (5\%).

Table 5 shows the prevalence of alcohol consumption in India by background characteristics of IHDS-II (20112012). There was a substantial relationship between alcohol consumption and age, with the increasing of age group, the consumption of alcohol also growing up. The higher alcohol consumption exposed in the age group 50-59 years (8.26\%) and followed by 40-49 age group (8.06 per cent) on a daily basis. In the light of sex, more percentage of males consume alcohol in all the categories (rarely: $7.42 \%$, sometimes: $24.82 \%$, and daily: $7.88 \%$ ) than the counterpart of females (rarely: $1.66 \%$, sometimes: $4.73 \%$, and daily: $1.90 \%$ ). The present study uncovered Muslims had the lowest alcohol consumption in all the categories (rarely: 2.91\%, sometimes: 4.58\%, and daily: $2.47 \%$ respectively) than any others religions on the one hand, on the other hand, Sikhs had the highest alcohol consumption in sometimes $(57.10 \%)$ and daily $(15.00 \%)$ categories. Among all social groups, STs $(11.00 \%)$ placed in the first rank followed by SCs (8.30\%) on a daily basis alcohol consumption than rest of 
Alcohol Consumption in India: An Analysis of IHDS Data

the categories. Those who have no education had the highest consumption of alcohol in both categories daily $(22 \%)$ and sometimes $(7.51 \%)$ as compared to graduate and higher educated. The study also found that urban (34.4\%) population have more alcohol consumption than rural population (35\%), and interestingly the study also found that migrants (39\%) are more vulnerable to use of alcohol than their counterpart of non-migrants (34.5\%).

Table 6 shows binary logistic regression results for alcohol consumption by using IHDS-II (2011-12) data. The alcohol consumption of age group 20-29 is 2.73 times (95\% CI: 2.27-3.27), age group 31-39 is 3.62 times (95\% CI: 3.03-4.32), age group 40-49 is 3.59 times (95\% CI: 3.01-4.28), age group 50-59 is 2.98 times (95\% CI: 2.49 3.56) times and age group above 60 is 2.11 times (95\% CI: 1.76-2.53) more likely to consume alcohol than the reference category of below 20 years' age group. Females are less likely to use alcohol than their counterparts. But in social groups, STs are more than two times (95\% CI: 2.36-2.86), and SCs are more than 1.6 times (95\% CI: 1.54-1.79) more likely than the reference category. Likewise, poor are less likely to use than non-poor. In aspects of the place of residence, urban areas are more than 1.2 times more likely to use alcohol (95\% CI: 0.951.12) than in rural areas. Similarly, migrants are more likely to use alcohol than inhabitants.

Table1. Percentage Distribution of Alcohol Consumption in India, (IHDS, 2004-05)

\begin{tabular}{|c|c|c|c|c|}
\hline Sates & Never (\%) & Sometimes (\%) & Daily (\%) & Total (N) \\
\hline Jammu \& Kashmir & 83.5 & 15.4 & 1.1 & 461 \\
\hline Himachal Pradesh & 27.9 & 66.7 & 5.4 & 847 \\
\hline Punjab & 20.0 & 68.8 & 11.3 & 752 \\
\hline Chandigarh & 5.0 & 90.0 & 5.0 & 20 \\
\hline Uttaranchal & 47.1 & 42.9 & 10.0 & 210 \\
\hline Haryana & 56.1 & 37.9 & 5.9 & 1,028 \\
\hline Delhi & 66.7 & 29.3 & 4.1 & 468 \\
\hline Rajasthan & 68.1 & 23.7 & 8.3 & 1,255 \\
\hline Uttar Pradesh & 73.3 & 21.1 & 5.6 & 2,147 \\
\hline Bihar & 34.0 & 18.8 & 47.2 & 930 \\
\hline Sikkim & 17.8 & 82.2 & 0.0 & 129 \\
\hline Arunachal Pradesh & 28.6 & 67.0 & 4.4 & 206 \\
\hline Nagaland & 27.3 & 67.1 & 5.7 & 88 \\
\hline Manipur & 97.6 & 2.4 & 0.0 & 83 \\
\hline Mizoram & 96.8 & 2.0 & 1.2 & 252 \\
\hline Tripura & 55.0 & 40.5 & 4.5 & 422 \\
\hline Meghalaya & 88.2 & 9.2 & 2.6 & 228 \\
\hline Assam & 67.5 & 26.0 & 6.5 & 889 \\
\hline West Bengal & 75.7 & 18.2 & 6.2 & 1,861 \\
\hline Jharkhand & 50.0 & 39.4 & 10.6 & 500 \\
\hline Orissa & 65.5 & 23.6 & 11.0 & 2,177 \\
\hline Chhattisgarh & 41.3 & 53.1 & 5.6 & 898 \\
\hline Madhya Pradesh & 82.7 & 15.0 & 2.4 & 2,582 \\
\hline Gujarat & 73.3 & 21.7 & 5.0 & 1,322 \\
\hline Daman \& Diu & 38.5 & 30.8 & 30.8 & 26 \\
\hline
\end{tabular}


Alcohol Consumption in India: An Analysis of IHDS Data

\begin{tabular}{|l|l|l|l|l|}
\hline \hline Dadra \& Nagar Haveli & 25.8 & 12.9 & 61.3 & 31 \\
\hline Maharashtra & 69.3 & 19.4 & 11.3 & 2,301 \\
\hline Andhra Pradesh & 30.3 & 43.5 & 26.2 & 1,266 \\
\hline Karnataka & 74.5 & 9.0 & 16.5 & 2,518 \\
\hline Goa & 47.8 & 23.9 & 28.3 & 46 \\
\hline Kerala & 54.0 & 35.5 & 10.5 & 693 \\
\hline Tamil Nadu & 50.5 & 37.2 & 12.3 & 853 \\
\hline Pondicherry & 6.5 & 67.7 & 25.8 & 31 \\
\hline India & 62.6 & 27.2 & 10.2 & 27,520 \\
\hline
\end{tabular}

Table2. Percentage Distribution of Alcohol Consumption in India and States (IHDS 2011-12)

\begin{tabular}{|l|l|l|l|l|l|}
\hline State & Never (\%) & Rarely (\%) & Sometimes (\%) & Daily (\%) & Total (N) \\
\hline Jammu \& Kashmir & 67.0 & 2.7 & 25.9 & 4.5 & 485 \\
\hline Himachal Pradesh & 31.9 & 4.8 & 58.4 & 5.0 & 961 \\
\hline Punjab & 25.8 & 8.8 & 51.6 & 13.8 & 968 \\
\hline Chandigarh & 25.0 & 13.9 & 50.0 & 11.1 & 36 \\
\hline Uttarakhand & 46.3 & 7.0 & 39.3 & 7.5 & 394 \\
\hline Haryana & 57.5 & 5.2 & 26.7 & 10.6 & 1,354 \\
\hline Delhi & 64.2 & 3.8 & 25.1 & 6.9 & 676 \\
\hline Rajasthan & 76.9 & 2.3 & 16.7 & 4.1 & 2,445 \\
\hline Uttar Pradesh & 78.6 & 6.1 & 13.0 & 2.3 & 4,294 \\
\hline Bihar & 53.1 & 5.6 & 32.7 & 8.7 & 1,172 \\
\hline Sikkim & 25.6 & 4.7 & 43.0 & 26.8 & 117 \\
\hline Arunachal Pradesh & 45.9 & 20.1 & 10.4 & 23.7 & 147 \\
\hline Nagaland & 43.6 & 7.9 & 46.9 & 1.6 & 35 \\
\hline Manipur & 0.0 & 0.0 & 100.0 & 0.0 & 15 \\
\hline Mizoram & 52.3 & 27.0 & 20.7 & 0.0 & 95 \\
\hline Tripura & 63.9 & 14.6 & 15.7 & 5.8 & 314 \\
\hline Meghalaya & 70.4 & 17.0 & 11.0 & 1.6 & 121 \\
\hline Assam & 46.2 & 23.1 & 23.6 & 7.2 & 748 \\
\hline West Bengal & 76.5 & 7.5 & 12.7 & 3.4 & 1,887 \\
\hline Jharkhand & 49.4 & 5.4 & 35.3 & 9.9 & 750 \\
\hline Orisha & 69.6 & 11.9 & 11.7 & 6.9 & 2,397 \\
\hline Chhattisgarh & 46.7 & 4.0 & 45.9 & 3.3 & 1,557 \\
\hline Madhya Pradesh & 75.1 & 4.0 & 18.2 & 2.7 & 3,369 \\
\hline Gujarat & 87.4 & 1.8 & 3.5 & 7.3 & 1,486 \\
\hline Daman \& Diu & 37.4 & 3.0 & 11.9 & 47.7 & 41 \\
\hline Dadra Nagar Haveli & 37.7 & 1.6 & 30.3 & 30.4 & 53 \\
\hline Maharashtra & 75.4 & 6.3 & 13.4 & 4.9 & 2,544 \\
\hline Andhra Pradesh & 19.5 & 5.5 & 49.0 & 26.0 & 1,088 \\
\hline Karnataka & 70.4 & 4.6 & 13.5 & 11.5 & 2,823 \\
\hline \hline American & & & \\
\hline
\end{tabular}


Alcohol Consumption in India: An Analysis of IHDS Data

\begin{tabular}{|l|l|l|l|l|l|}
\hline Goa & 5.1 & 4.7 & 28.6 & 61.6 & 57 \\
\hline Kerala & 35.5 & 22.4 & 32.2 & 9.8 & 586 \\
\hline Tamil Nadu & 55.2 & 6.3 & 26.8 & 11.8 & 1,053 \\
\hline Pondicherry & 4.9 & 4.9 & 11.0 & 79.2 & 11 \\
\hline India & 65.3 & 6.5 & 21.4 & 6.9 & 34,079 \\
\hline
\end{tabular}

Table3. Percentage Distribution of Alcohol Consumption in India and States (IHDS, 2004-05)

\begin{tabular}{|c|c|c|c|}
\hline States & Never Consumed (\%) & Ever consumed (\%) & Total (N) \\
\hline Jammu \& Kashmir & 83.5 & 16.5 & 461 \\
\hline Himachal Pradesh & 27.9 & 72.1 & 847 \\
\hline Punjab & 20.0 & 80.1 & 752 \\
\hline Chandigarh & 5.0 & 95.0 & 20 \\
\hline Uttaranchal & 47.1 & 52.9 & 210 \\
\hline Haryana & 56.1 & 43.9 & 1,028 \\
\hline Delhi & 66.7 & 33.3 & 468 \\
\hline Rajasthan & 68.1 & 32.0 & 1,255 \\
\hline Uttar Pradesh & 73.3 & 26.7 & 2,147 \\
\hline Bihar & 34.0 & 66.0 & 930 \\
\hline Sikkim & 17.8 & 82.2 & 129 \\
\hline Arunachal Pradesh & 28.6 & 71.4 & 206 \\
\hline Nagaland & 27.3 & 72.7 & 88 \\
\hline Manipur & 97.6 & 2.4 & 83 \\
\hline Mizoram & 96.8 & 3.2 & 252 \\
\hline Tripura & 55.0 & 45.0 & 422 \\
\hline Meghalaya & 88.2 & 11.8 & 228 \\
\hline Assam & 67.5 & 32.5 & 889 \\
\hline West Bengal & 75.7 & 24.3 & 1,861 \\
\hline Jharkhand & 50.0 & 50.0 & 500 \\
\hline Orissa & 65.5 & 34.5 & 2,177 \\
\hline Chhattisgarh & 41.3 & 58.7 & 898 \\
\hline Madhya Pradesh & 82.7 & 17.3 & 2,582 \\
\hline Gujarat & 73.3 & 26.7 & 1,322 \\
\hline Daman \& Diu & 38.5 & 61.5 & 26 \\
\hline Dadra Nagar Haveli & 25.8 & 74.2 & 31 \\
\hline Maharashtra & 69.3 & 30.7 & 2,301 \\
\hline Andhra Pradesh & 30.3 & 69.8 & 1,266 \\
\hline Karnataka & 74.5 & 25.5 & 2,518 \\
\hline Goa & 47.8 & 52.2 & 46 \\
\hline Kerala & 54.0 & 46.0 & 693 \\
\hline Tamil Nadu & 50.5 & 49.5 & 853 \\
\hline Pondicherry & 6.5 & 93.6 & 31 \\
\hline India & 62.6 & 37.4 & 27,520 \\
\hline
\end{tabular}


Alcohol Consumption in India: An Analysis of IHDS Data

Table4. Percentage Distribution of Alcohol Consumption in India and States (IHDS, 2011-12)

\begin{tabular}{|c|c|c|c|}
\hline States & Never Consumed (\%) & Ever consumed (\%) & Total (N) \\
\hline Jammu \& Kashmir & 67.0 & 33.0 & 485 \\
\hline Himachal Pradesh & 31.9 & 68.2 & 961 \\
\hline Punjab & 25.8 & 74.2 & 968 \\
\hline Chandigarh & 25.0 & 75.0 & 36 \\
\hline Uttarakhand & 46.3 & 53.7 & 394 \\
\hline Haryana & 57.5 & 42.5 & 1,354 \\
\hline Delhi & 64.2 & 35.8 & 676 \\
\hline Rajasthan & 76.9 & 23.1 & 2,445 \\
\hline Uttar Pradesh & 78.6 & 21.4 & 4,294 \\
\hline Bihar & 53.1 & 46.9 & 1,172 \\
\hline Sikkim & 25.6 & 74.5 & 117 \\
\hline Arunachal Pradesh & 45.9 & 54.2 & 147 \\
\hline Nagaland & 43.6 & 56.4 & 35 \\
\hline Manipur & 0.0 & 100.0 & 15 \\
\hline Mizoram & 52.3 & 47.7 & 95 \\
\hline Tripura & 63.9 & 36.1 & 314 \\
\hline Meghalaya & 70.4 & 29.6 & 121 \\
\hline Assam & 46.2 & 53.9 & 748 \\
\hline West Bengal & 76.5 & 23.6 & 1,887 \\
\hline Jharkhand & 49.4 & 50.6 & 750 \\
\hline Orissa & 69.6 & 30.4 & 2,397 \\
\hline Chhattisgarh & 46.7 & 53.3 & 1,557 \\
\hline Madhya Pradesh & 75.1 & 24.9 & 3,369 \\
\hline Gujarat & 87.4 & 12.6 & 1,486 \\
\hline Daman \& Diu & 37.4 & 62.6 & 41 \\
\hline Dadra Nagar Haveli & 37.7 & 62.3 & 53 \\
\hline Maharashtra & 75.4 & 24.6 & 2,544 \\
\hline Andhra Pradesh & 19.5 & 80.6 & 1,088 \\
\hline Karnataka & 70.4 & 29.6 & 2,823 \\
\hline Goa & 5.1 & 94.9 & 57 \\
\hline Kerala & 35.5 & 64.5 & 586 \\
\hline Tamil Nadu & 55.2 & 44.8 & 1,053 \\
\hline Pondicherry & 4.9 & 95.1 & 11 \\
\hline India & 65.3 & 34.7 & 34,079 \\
\hline
\end{tabular}


Alcohol Consumption in India: An Analysis of IHDS Data

Table5. Prevalence of Alcohol Consumption by Background Characteristics, 2011-12

\begin{tabular}{|c|c|c|c|c|c|c|}
\hline Background Characteristics & Never (\%) & Rarely (\%) & Some-times (\%) & Daily (\%) & Total (N) & chi2 \\
\hline \multicolumn{7}{|l|}{ Age of the respondent } \\
\hline$<20$ & 84.81 & 5.79 & 6.55 & 2.85 & 783 & \multirow{6}{*}{$-631.61^{* *}$} \\
\hline 20-29 & 65.40 & 7.74 & 21.75 & 5.12 & 4,529 & \\
\hline 30-39 & 58.30 & 7.61 & 26.66 & 7.44 & 7,203 & \\
\hline $40-49$ & 60.85 & 6.54 & 24.55 & 8.06 & 8,086 & \\
\hline 50-59 & 66.15 & 5.82 & 19.76 & 8.26 & 6,400 & \\
\hline 60 and & 73.54 & 5.07 & 16.03 & 5.36 & 7,078 & \\
\hline \multicolumn{7}{|l|}{ Sex } \\
\hline \begin{tabular}{|l|} 
Male \\
\end{tabular} & 59.88 & 7.42 & 24.82 & 7.88 & 28,297 & \multirow{2}{*}{$2200^{* * *}$} \\
\hline Female & 91.72 & 1.66 & 4.73 & 1.90 & 5,782 & \\
\hline \multicolumn{7}{|l|}{ Religion } \\
\hline Hindu & 63.38 & 6.59 & 22.76 & 7.27 & 28,227 & \multirow{5}{*}{$2100^{* * *}$} \\
\hline Muslim & 90.04 & 2.91 & 4.58 & 2.47 & 3,977 & \\
\hline Christian & 41.83 & 14.15 & 31.50 & 12.52 & 809 & \\
\hline Sikh & 19.83 & 8.07 & 57.1 & 15.00 & 483 & \\
\hline Others & 47.10 & 11.25 & 34.69 & 6.96 & 583 & \\
\hline \multicolumn{7}{|l|}{ Caste } \\
\hline General & 74.70 & 5.78 & 15.00 & 4.31 & 8,114 & \multirow{5}{*}{$897.5^{* * *}$} \\
\hline OBC & 68.58 & 5.46 & 20.00 & 6.38 & 13,644 & \\
\hline $\mathrm{SC}$ & 59.25 & 7.35 & 25.00 & 8.30 & 8,003 & \\
\hline ST & 47.00 & 9.00 & 34.00 & 11.00 & 3,918 & \\
\hline Others & 73.00 & 9.06 & 11.96 & 6.12 & 355 & \\
\hline \multicolumn{7}{|l|}{ Economic Status } \\
\hline Non Poor & 65.64 & 6.36 & 21.08 & 6.92 & 26,828 & \multirow{2}{*}{0.83} \\
\hline Poor & 64.00 & 6.73 & 23.00 & 6.69 & 7,240 & \\
\hline \multicolumn{7}{|l|}{\begin{tabular}{|l|} 
Education of the $\mathrm{HH}$ \\
\end{tabular}} \\
\hline No Education & 64.00 & 5.86 & 22.00 & 7.51 & 23,118 & \multirow{5}{*}{$108.5^{* * *}$} \\
\hline Primary Education & 67.78 & 7.70 & 18.76 & 5.76 & 6,540 & \\
\hline Secondary Education & 66.00 & 8.00 & 22.00 & 5.00 & 3,395 & \\
\hline Higher Secondary & 64.00 & 11.00 & 21.00 & 5.00 & 415 & \\
\hline Graduate and Higher & 70.04 & 6.46 & 19.12 & 4.39 & 360 & \\
\hline \multicolumn{7}{|l|}{ Place of Residence } \\
\hline \begin{tabular}{|l|} 
Rural \\
\end{tabular} & 65.00 & 7.00 & 21.00 & 7.00 & 24,784 & \multirow{3}{*}{$6.75^{*}$} \\
\hline Urban & 64.64 & 6.26 & 21.52 & 7.58 & 9,295 & \\
\hline \multicolumn{6}{|l|}{ Migration Status } & \\
\hline No & 65.58 & 6.36 & 21.23 & 6.83 & 30,223 & \multirow{2}{*}{$-8.82^{* *}$} \\
\hline Yes & 61.00 & 7.00 & 23.00 & 8.00 & 3,271 & \\
\hline Total & 65.27 & 6.45 & 21.42 & 6.86 & 34,079 & \\
\hline
\end{tabular}


Alcohol Consumption in India: An Analysis of IHDS Data

Table6. Determinants of Alcohol Consumption by Background Characteristics, 2011-12

\begin{tabular}{|c|c|c|c|}
\hline \multirow[t]{2}{*}{ Background Characteristics } & \multirow[t]{2}{*}{ Odds Ratio } & \multicolumn{2}{|c|}{ [95\% Conf.Interval] } \\
\hline & & Lower & Upper \\
\hline \multicolumn{4}{|l|}{ Age of the respondent } \\
\hline \multicolumn{4}{|l|}{$<20 \AA$} \\
\hline $20-29$ & $2.73^{* * *}$ & 2.276 & 3.277 \\
\hline $30-39$ & $3.62^{* * *}$ & 3.035 & 4.326 \\
\hline $40-49$ & $3.59^{* * *}$ & 3.012 & 4.288 \\
\hline $50-59$ & $2.98^{* * *}$ & 2.498 & 3.561 \\
\hline 60 and & $2.11^{* * *}$ & 1.761 & 2.531 \\
\hline \multicolumn{4}{|l|}{ Sex } \\
\hline \multicolumn{4}{|l|}{ Male $\AA$} \\
\hline Female & $0.11^{* * *}$ & 0.106 & 0.130 \\
\hline \multicolumn{4}{|l|}{ Religion } \\
\hline \multicolumn{4}{|l|}{ Hindu® } \\
\hline Muslim & 0.19 & 0.217 & 0.215 \\
\hline Christian & 2.18 & 2.565 & 2.734 \\
\hline Sikh & 7.47 & 9.608 & 9.827 \\
\hline Others & 1.33 & 1.609 & 1.641 \\
\hline \multicolumn{4}{|l|}{ Caste } \\
\hline \multicolumn{4}{|l|}{ General $®$} \\
\hline $\mathrm{OBC}$ & $1.12^{* * *}$ & 1.051 & 1.201 \\
\hline $\mathrm{SC}$ & $1.66^{* * *}$ & 1.545 & 1.793 \\
\hline ST & $2.60^{* * *}$ & 2.363 & 2.861 \\
\hline Others & $1.45^{* * *}$ & 1.122 & 1.890 \\
\hline \multicolumn{4}{|l|}{\begin{tabular}{|l|} 
Economic Status \\
\end{tabular}} \\
\hline \multicolumn{4}{|l|}{ Non Poor® } \\
\hline Poor & $0.97^{* *}$ & 0.915 & 1.037 \\
\hline \multicolumn{4}{|l|}{ Education of the $\mathrm{HH}$} \\
\hline \multicolumn{4}{|l|}{ No Education $®$} \\
\hline Primary Education & $0.85^{* * *}$ & 0.798 & 0.908 \\
\hline secondary Education & 0.94 & 0.863 & 1.024 \\
\hline Higher Secondary & 0.92 & 0.744 & 1.156 \\
\hline Graduate and Higher & $0.73^{* * *}$ & 0.576 & 0.929 \\
\hline \multicolumn{4}{|l|}{ Place of Residence } \\
\hline \multicolumn{4}{|l|}{ Rural $\AA$} \\
\hline Urban & $1.23^{* * *}$ & 1.165 & 1.308 \\
\hline \multicolumn{4}{|l|}{ Migration Status } \\
\hline \multicolumn{4}{|l|}{ No® } \\
\hline Yes & $1.03^{* *}$ & 0.953 & 1.127 \\
\hline
\end{tabular}


Alcohol Consumption in India: An Analysis of IHDS Data
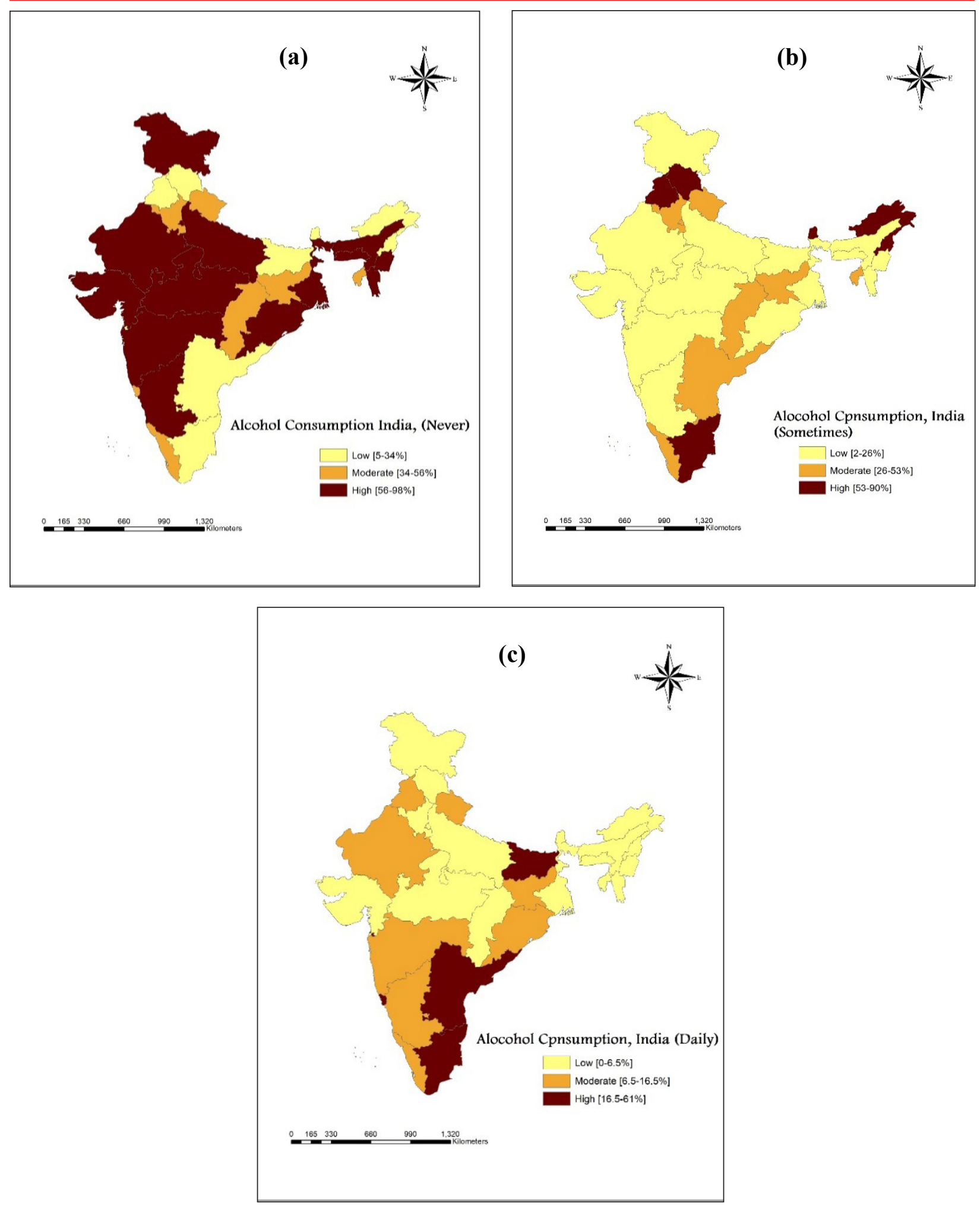

Map1. India's geographic percent distribution of alcohol consumption (a) Never (b) Sometimes (c) Daily, IHDS2004-05. Sources: Authors generated the maps by using ArcGIS 10.1. 
Alcohol Consumption in India: An Analysis of IHDS Data
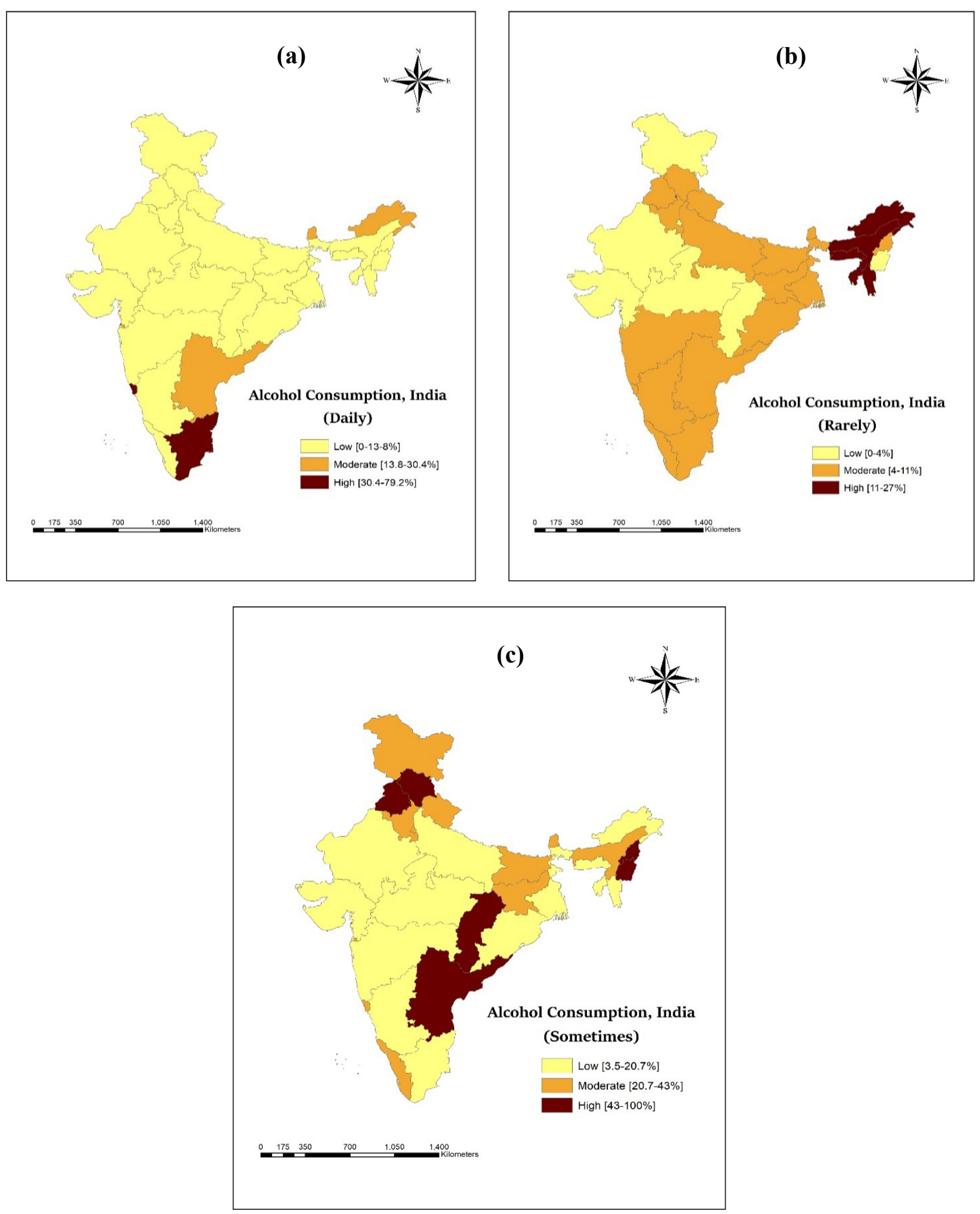

Map2. India's geographic percent distribution of alcohol consumption (a) Daily (b) Rarely (c) Sometimes, IHDS2011-12. Sources: Authors generated the maps by using ArcGIS 10.1. 


\section{DISCUSSION AND CONCLUSION}

The present study found there is a large variation in alcohol consumption among the different age groups, religion, place of residence, sexes, caste and economic status in different states and UTs of India which is a very consistent result with other studies (Bhullar et al., 2013). More than half of India's population never used alcohol while about 37 per cent have used frequently (Sometimes \& Daily) which is counterintuitive result with several studies (Prasad, 2009; Sarkar et al., 2013) which found that the prevalence of alcohol consumption in India is reported to be around 20 per cent. It is found that three states/UTs, i.e. Bihar, Daman \& Diu, Dadra \& Nagar Haveli had the high consumption of alcohol where more than 30 per cent of people consuming alcohol on a daily basis. Moreover, eight states/UTs like Punjab, Chandigarh, Sikkim, Arunachal Pradesh, Nagaland, Chhattisgarh, and Pondicherry had 50 or more than 50 per cent of alcohol consumption on sometimes basis. There were seven states/UTs (Pondicherry, Goa, Andhra Pradesh, Daman \& Diu, Dadra Nagar Haveli, Arunachal Pradesh, and Sikkim) which had 20 per cent or more use daily alcohol consumption. 21 states/UTs had 20 or more than 20 per cent sometimes alcohol users whereas, only four states were found 20 per cent or more in the rare basis of alcohol consumption. In IHDS 2004-05, 63 per cent were never consumed alcohol, and the remaining 37 per cent were ever consumed of alcohol. The study showed there is a slight decrease of 2 per cent in alcohol consumption from IHDS (2004-05) to IHDS (2011-12) in India. Although the situation was not similar for all states, there were some states where the consumption of alcohol had increased from 2004 to 2012 like Jammu and Kashmir (16\%), Mizoram (44\%) and Kerala (19\%). In contrary to that, there were also a few states which decreased the alcohol consumption from 2004 to 12 like Rajasthan (8\%) and Tamil Nadu (5\%).

The relationship between alcohol consumption and age indicates that, there was a positive relationship, with the increasing of age group, the consumption of alcohol also growing up and this finding is very much consistent with several existing studies (Wilsnack et al., 2009; Nadkarni et al., 2013; Goodwin et al., 1987; Australian Institute of Health and Welfare, 2010). In the light of sex, more percentage of males consume alcohol in all the categories than the counterpart of females which is the similar result with many others studies (Goodwin et al., 1987; Wilsnack et al., 2009; Roche and Deehan, 2002; Rahav et al., 2006). The present study uncovered Muslims are the lowest alcohol consumers in all the categories than any others religion on the one hand, on the other hand, Sikhs had the highest alcohol consumption in sometimes and daily categories and the same result came up with several other studies (Subramanian et al., 2005; Gupta et al., 2003). Among all social groups, STs placed in the first rank followed by SCs in the daily basis alcohol consumption than rest categories. Those who have no education had the highest use of alcohol in both categories daily and sometimes as compared to graduate and higher educated. The study also found that urban population had more alcohol consumption than rural population, and interestingly the study also found that migrants are more vulnerable to use of alcohol than their counterpart of non-migrants. One study (Gupta et al., 2003) done by Gupta in 2003 showed that the prevalence by religion had most wider variations which very much consistent with the present study.

Thus there is an essential need to address the issue of alcohol consumption in India where the country has different patterns and levels of alcohol consumption among the different states and UTs of India. Public policies and awareness are needed to address differentials needs of men and women and different age groups among the population. Special attention is needed to address the problem in low social groups where the consumption of alcohol is high.

\section{Strengths and Limitations}

The data source (India Human Development Survey) covered all the states of India except Lakshadweep, and Andaman and Nicobar Islands, and it comprises a full range of human development issues, not single focus projects. Alcohol consumption was not self-reported by the participants; the head of the household was asked 
about all the members of his or her family ("Does anyone of your household drink alcohol"), So there could be a chance for bias answer because head of the household is giving answer on behalf of someone else's drinking behaviour.

\section{Informed Consent}

No primary data were collected for this study, so informed consent was not obtained from individual participants in the study.

\section{Ethical Treatment of Experimental Subjects (Animal and Human)}

Present study did not contain any studies either with human or animal participants performed by any of the authors.

\section{Ethical Statement}

The study is based on secondary (publicly available) data and no ethical issues are involved.

\section{Funding}

This research did not receive any grant from any funding agency in the public, commercial, or not-for-profit sectors.

\section{Acknowledgments}

This study would not have been possible without the enthusiastic cooperation as well as the advice of my respected professor R. Nagarajan as well as two of my best seniors Bal Govind Chauhan and Ambarish Roy.

\section{REFERENCES}

1. Australian Institute of Health and Welfare. (2010). 2010 National drug strategy household survey report. Australian Institute of Health and Welfare.

2. Babor, T. F., Babor, T., Caetano, R., Casswell, S., Edwards, G., \& Giesbrecht, N. (2010). Alcohol: no ordinary commodity: research and public policy. Oxford University Press.

3. Benegal, V., Gururaj, G., \& Murthy, P. (2002). Project report on a WHO multicentre collaborative project on establishing and monitoring alcohol's involvement in casualties, 2000-01. Bangalore: NIMHANS.

4. Bhullar, D. S., Singh, S. P., Thind, A. S., Aggarwal, K. K., \& Goyal, A. (2013). Alcohol Drinking Patterns: A Sample Study. J Indian Acad Forensic Med [serial online] Mar, 35(1), 0971-097.

5. Boden, J. M., Fergusson, D. M., \& Horwood, L. J. (2013). Alcohol misuse and relationship breakdown: findings from a longitudinal birth cohort. Drug and alcohol dependence, 133(1), 115-120.

6. Casswell, S., Pledger, M., \& Hooper, R. (2003). Socioeconomic status and drinking patterns in young adults. Addiction, 98(5), 601-610.

7. Chowdhury, A. N., Ramakrishna, J., Chakraborty, A. K., \& Weiss, M. G. (2006). Cultural context and impact of alcohol use in the Sundarban Delta, West Bengal, India. Social Science \& Medicine, 63(3), 722-731.

8. Easwaran, M., Bazroy, J., Jayaseelan, V., \& Singh, Z. (2015). Prevalence and determinants of alcohol consumption among adult men in a coastal area of South India. Int J Med Sci Public Health, 4(3), 360-364.

9. Goodwin, J. S., Sanchez, C. J., Thomas, P., Hunt, C., Garry, P. J., \& Goodwin, J. M. (1987). Alcohol intake in a healthy elderly population. American journal of public health, 77(2), 173-177.

10. Gupta, P. C., Saxena, S., Pednekar, M. S., \& Maulik, P. K. (2003). Alcohol consumption among middle-aged and elderly men: a community study from western India. Alcohol and Alcoholism, 38(4), 327-331. 
Alcohol Consumption in India: An Analysis of IHDS Data

11. Gururaj, G. (2005). Injuries in India: A national perspective. Background Papers: Burden of Disease in India Equitable Development-Healthy Future. New Delhi: National Commission on Macroeconomics and Health, Ministry of Health \& Family Welfare, Government of India, 325-347.

12. Huckle, T., You, R. Q., \& Casswell, S. (2010). Socio-economic status predicts drinking patterns but not alcohol-related consequences independently. Addiction, 105(7), 1192-1202.

13. Liang, W., \& Chikritzhs, T. (2012). Brief report: marital status and alcohol consumption behaviours. Journal of Substance Use, 17(1), 84-90.

14. Matzger, H., Delucchi, K., Weisner, C., \& Ammon, L. (2004). Does marital status predict long-term drinking? Five-year observations of dependent and problem drinkers. Journal of studies on alcohol, 65(2), 255-265.

15. Nadkarni, A., Murthy, P., Crome, I. B., \& Rao, R. (2013). Alcohol use and alcohol-use disorders among older adults in India: a literature review. Aging \& mental health, 17(8), 979-991.

16. Neufeld, K. J., Peters, D. H., Rani, M., Bonu, S., \& Brooner, R. K. (2005). Regular use of alcohol and tobacco in India and its association with age, gender, and poverty. Drug and alcohol dependence, 77(3), 283-291.

17. Pandey, S. K., Datta, D., Dutta, S., Verma, Y., \& Chakrabarti, A. (2015). Socioeconomic characteristics of alcohol and other substance users, seeking treatment in Sikkim, North East India. Journal of pharmacy \& bioallied sciences, 7(2), 151.

18. Prasad, R. (2009). Alcohol use on the rise in India. The Lancet, 373(9657), 17-18.

19. Rahav, G., Wilsnack, R., Bloomfield, K., Gmel, G., \& Kuntsche, S. (2006). The influence of societal level factors on men's and women's alcohol consumption and alcohol problems. Alcohol and Alcoholism, 41(suppl_1), i47-i55.

20. Ray, R. (2004). The extent, pattern and trends of drug abuse in India: National survey. Ministry of Social Justice and Empowerment, Government of India \& United Nations Office on Drugs and Crime, Regional Office for South Asia.

21. Rehm, J., Mathers, C., Popova, S., Thavorncharoensap, M., Teerawattananon, Y., \& Patra, J. (2009). Global burden of disease and injury and economic cost attributable to alcohol use and alcohol-use disorders. The lancet, 373(9682), 2223-2233.

22. Rice, N., Carr-Hill, R., Dixon, P., \& Sutton, M. (1998). The influence of households on drinking behaviour: a multilevel analysis. Social Science \& Medicine, 46(8), 971-979.

23. Roche, A. M., \& Deehan, A. N. N. (2002). Women's alcohol consumption: emerging patterns, problems and public health implications. Drug and alcohol review, 21(2), 169-178.

24. Sarkar, A. P., Sen, S., Mondal, S., Singh, O. P., Chakraborty, A., \& Swaika, B. (2013). A study on socio-demographic characteristics of alcoholics attending the de-addiction center at Burdwan medical college and hospital in West Bengal. Indian journal of public health, 57(1), 33.

25. Schmidt, L. A., Mäkelä, P., Rehm, J., \& Room, R. (2010). Alcohol: equity and social determinants. Equity, social determinants and public health programmes, 11,30.

26. Singh, Z., \& Mail, I. D. (2014). Alcohol or health: choice is yours. Health, 2(4).

27. Subramanian, S. V., Nandy, S., Irving, M., Gordon, D., \& Smith, G. D. (2005). Role of socioeconomic markers and state prohibition policy in predicting alcohol consumption among men and women in India: a multilevel statistical analysis. Bulletin of the World Health Organization, 83, 829-836. 
28. Thapa, N., Aryal, K. K., Puri, R., Shrestha, S., Shrestha, S., Thapa, P., ... \& Stray-Pedersen, B. (2016). Alcohol consumption practices among married women of reproductive age in Nepal: a population based household survey. PloS one, 11(4), e0152535.

29. WHO. (2018). Global status report on alcohol and health. Last accessed (14-10-2018) http://apps.who.int/ iris/bitstream/handle/10665/274603/9789241565639-eng.pdf?ua=1

30. Wilsnack, R. W., Wilsnack, S. C., Kristjanson, A. F., Vogeltanz-Holm, N. D., \& Gmel, G. (2009). Gender and alcohol consumption: patterns from the multinational GENACIS project. Addiction, 104(9), 1487-1500.

31. World Health Organization, \& World Health Organization. Management of Substance Abuse Unit. (2014). Global status report on alcohol and health, 2014. World Health Organization. Last accessed (2-11-2018) http://apps.who.int/iris/bitstream/handle/10665/112736/9789240692763_eng.pdf;jsessionid=8149F 1D36A48FBB5C18DCD915BD0253C?sequence=1

Citation: Nasim Ahamed Mondal, Mithun Mog, Kacho Amir Khan. "Alcohol Consumption in India: An Analysis of IHDS Data" American Research Journal of Humanities and Social Sciences, vol 4, no. 1, 2018, pp. 1-15.

Copyright (c) 2018 Nasim Ahamed Mondal, Mithun Mog, Kacho Amir Khan, This is an open access article distributed under the Creative Commons Attribution License, which permits unrestricted use, distribution, and reproduction in any medium, provided the original work is properly cited. 